\title{
Relation Between Folate Status, a Common Mutation in Methylenetetrahydrofolate Reductase, and Plasma Homocysteine Concentrations
}

1. Paul F. Jacques, ScD;

2. Andrew G. Bostom, MD, MS;

3. Roger R. Williams, MD;

4. R. Curtis Ellison, MD, MS;

5. John H. Eckfeldt, MD, PhD;

6. Irwin H. Rosenberg, MD;

7. Jacob Selhub, PhD;

8. Rima Rozen, $\mathrm{PhD}$

\pm Author Affiliations

1. From the Jean Mayer USDA Human Nutrition Research Center on Aging at Tufts University, Boston, Mass (P.F.J., A.G.B., I.H.R., J.S.); the NHLBI Family Heart Study, University of Utah Cardiovascular Genetics Research Clinic, Salt Lake City (R.R.W.); the NHLBI Family Heart Study, Framingham, Mass, and Boston (Mass) University School of Medicine (R.C.E.); the NHLBI Family Heart Study Central Laboratory, Department of Laboratory Medicine and Pathology, University of Minnesota, Minneapolis (J.H.E.); and the Departments of Human Genetics, Pediatrics, and Biology, McGill University, Montreal (Quebec) Children's Hospital (R.R.).

1. Correspondence to Rima Rozen, Montreal Children's Hospital, 2300 Tupper St, Montreal, Quebec, Canada H3H 1 P3.

\section{$\underline{\text { Next Section }}$}

\section{Abstract}

Background Methylenetetrahydrofolate reductase (MTHFR) synthesizes 5methyltetrahydrofolate, the major carbon donor in remethylation of homocysteine to methionine. A common MTHFR mutation, an alanine-to-valine substitution, renders the enzyme thermolabile and may cause elevated plasma levels of the amino acid homocysteine.

Methods and Results To assess the potential interaction between this mutation and vitamin coenzymes in homocysteine metabolism, we screened 365 individuals from the NHLBI Family Heart Study. Among individuals with lower plasma folate concentrations $(<15.4 \mathrm{nmol} / \mathrm{L})$, those with the homozygous mutant genotype had total fasting homocysteine levels that were $24 \%$ 
greater $(P<.05)$ than individuals with the normal genotype. A difference between genotypes was not seen among individuals with folate levels $\geq 15.4 \mathrm{nmol} / \mathrm{L}$.

Conclusions Individuals with thermolabile MTHFR may have a higher folate requirement for regulation of plasma homocysteine concentrations; folate supplementation may be necessary to prevent fasting hyperhomocysteinemia in such persons.

Key Words:

- $\quad$ enzymes

- homocysteine

- $\underline{\text { amino acids }}$

- $\underline{\text { metabolism }}$

- genetics

Homocysteine is a sulfur amino acid whose metabolism is at the intersection of two metabolic pathways: remethylation and transsulfuration. ${ }^{1}$ In remethylation, the primary methyl donor for the vitamin $B_{12}$-dependent conversion of homocysteine to methionine is 5methyltetrahydrofolate, the principal circulating form of folate. 5-Methyltetrahydrofolate is synthesized from 5,10-methylenetetrahydrofolate by the enzyme MTHFR. In the transsulfuration pathway, homocysteine condenses with serine to form cystathionine in an irreversible reaction catalyzed by the PLP-containing enzyme CBS. These pathways can be disrupted by genetic defects in the two enzymes CBS and MTHFR or by deficiencies of folate, vitamin $\mathrm{B}_{12}$, and vitamin $\mathrm{B}_{6}$.

Because of the existence of a cellular homocysteine export mechanism, plasma normally contains a small amount of homocysteine, averaging $10 \mu \mathrm{mol} / \mathrm{L} . \stackrel{2}{ }$ This export mechanism complements the catabolism of homocysteine to help maintain low intracellular concentrations of this potentially cytotoxic sulfur amino acid. In hyperhomocysteinemia, plasma homocysteine concentrations are elevated, indicating that homocysteine metabolism has in some way been disrupted. The more severe cases of hyperhomocysteinemia are primarily due to defects in the genes encoding $\mathrm{CBS}^{\underline{3}}$ and MTHFR. ${ }^{4}$

A potential consequence of even moderate elevations of plasma homocysteine may be an increased risk of occlusive vascular disease. ${ }^{5}$ Accordingly, investigation of the determinants of moderate hyperhomocysteinemia has intensified. Inadequate status of nutritional coenzymes in homocysteine metabolism, at least in the elderly, appears to be a major determinant of moderate hyperhomocysteinemia..$^{\underline{6}}$ However, recent evidence suggests that common enzyme mutations may also be important determinants of hyperhomocysteinemia. In 1988, Kang et $\mathrm{al}^{7}$ reported a $^{-}$ variant of MTHFR that was distinguishable from the normal enzyme by its lower specific activity and its heat sensitivity and suggested that this thermolabile variant was an inherited autosomal recessive trait that is present in $\approx 5 \%$ of the general population and $17 \%$ of patients with coronary disease. ${ }^{-}$Subsequently, one of us (R.R.) and coworkers isolated the cDNA for human MTHFR $^{4}$ and demonstrated that thermolabile MTHFR is caused by an alanine-to-valine (Ala-to-Val) missense mutation. ${ }^{-}$Twelve percent of French Canadians were shown to have the homozygous mutant genotype for this polymorphic variant. ${ }^{-}$ 
The impact of thermolabile MTHFR on hyperhomocysteinemia remains equivocal. Kang et $\mathrm{al}^{\underline{8}}$ demonstrated that even though plasma homocysteine levels were higher among individuals with thermolabile MTHFR than among those with normal enzyme activity, many of those with the thermolabile enzyme did not have hyperhomocysteinemia. Furthermore, the hyperhomocysteinemia seen in the original study of Kang et $\mathrm{al}^{7}$ was associated with low plasma folate concentrations, and folate supplementation normalized the plasma homocysteine concentrations. These data suggested that folate status might play a crucial role in the development of hyperhomocysteinemia in individuals with the thermolabile defect.

To test the hypothesis that homocysteine concentrations in individuals with thermolabile MTHFR are dependent on folate status, we examined the influence of plasma folate concentration on the relation between the MTHFR thermolabile polymorphism and plasma homocysteine concentrations, using data from the NHLBI FHS.

\section{Previous SectionNext Section}

\section{Methods}

\section{Subjects}

Subjects were participants in the NHLBI FHS. The FHS was established to evaluate genetic and nongenetic determinants of coronary heart disease in randomly sampled families and families known to be at high risk for coronary heart disease. Subject examinations began in February 1994 and are expected to be complete by January 1996. Two of the four sites participating in the FHS are involved in an ancillary homocysteine study, which is described in greater detail elsewhere. ${ }^{10}$ All persons at these sites undergoing the complete FHS phase II evaluation were invited to participate in the ancillary project, with the following exclusion criteria: age $<25$ or $>69$ years old, fasting for $<10$ hours, and lack of informed consent. This ancillary homocysteine study protocol was approved by the FHS Steering Committee and Safety Monitoring Board and the institutional review boards for Boston University School of Medicine, the University of Utah, and Tufts-New England Medical Center. These preliminary analyses are based on the initial 365 subjects enrolled in the ancillary homocysteine study.

\section{Fasting Blood Collection}

Immediately upon arriving, before methionine loading, subjects underwent fasting ( $>10$ hours) phlebotomy. One 10-mL EDTA-containing vacuum tube was obtained, and the plasma was promptly separated, divided into aliquots, and stored at $-70^{\circ} \mathrm{C}$. DNA was purified by a commercially available salt precipitation method (Puragene from Gentra Systems, Inc).

\section{Methionine Load Test}

Methionine $(100 \mathrm{mg} / \mathrm{kg})$ was administered in $200 \mathrm{~mL}$ of fruit juice immediately after the fasting phlebotomy. Four hours after the methionine load, a repeat plasma sample was obtained for homocysteine determination. 


\section{Laboratory Determinations}

As previously described, ${ }^{6}$ total homocysteine in plasma was determined by high-performance liquid chromatography with fluorometric detection, plasma folate by a 96-well plate microbial (Lactobacillus casei) assay, plasma PLP by the tyrosine decarboxylase apoenzyme method, and plasma vitamin $\mathrm{B}_{12}$ by a radioassay.

\section{MTHFR Genotype Determination}

The polymerase chain reaction primers for amplification of the MTHFR mutation have been described elsewhere. ${ }^{9}$ The primers generate a 198 -bp fragment. The MTHFR polymorphism, a C-to-T substitution at bp 677, creates a HinfI recognition sequence. If the mutation is present, HinfI digests the 198-bp fragment into a 175-bp and a 23-bp fragment. The fragments were analyzed by polyacrylamide gel electrophoresis.

\section{Statistical Methods}

All plasma measures were positively skewed, and we used logarithmic transformations to normalize their distributions. Thus, all means presented here are geometric means. To describe the relationships between MTHFR thermolabile genotype and plasma homocysteine and vitamin concentrations, we calculated the geometric mean levels of these factors in individuals with normal (Ala/Ala), heterozygous (Val/Ala), and homozygous (Val/Val) mutant genotypes. We used ANOVA to test for differences between genotypes and for interactions between genotype and vitamin levels. Because age and sex adjustment had no influence on the observed results, we present only the unadjusted data.

\section{Previous SectionNext Section}

\section{Results}

We measured total fasting and post-methionine load homocysteine concentrations. Mean total fasting homocysteine concentrations were slightly greater for homozygotes of the MTHFR thermolabile mutation, but there was a significant interaction between genotype and folate status (Table $\underline{\Downarrow})$. Among those with plasma folate levels below the sample median $(15.4 \mathrm{nmol} / \mathrm{L})$, the mean fasting homocysteine concentration was $24 \%$ greater $(P<.05)$ for homozygotes with the thermolabile mutation than for either the normal or heterozygous individuals. No association was observed between genotype and fasting homocysteine concentrations in those with plasma folate levels at or above the median. Neither PLP nor vitamin $\mathrm{B}_{12}$ modified the association between genotype and fasting homocysteine. Post-methionine load total homocysteine concentration was unrelated to MTHFR genotype (Table $\underline{\Downarrow}$ ) irrespective of plasma vitamin concentrations. Mean plasma vitamin concentrations were also unrelated to genotype.

View this table:

- $\underline{\text { In this window }}$ 
- $\underline{\text { In a new window }}$

Table 1.

Total Plasma Homocysteine by MTHFR Genotype

Previous SectionNext Section

\section{Discussion}

Our data qualify the role of thermolabile MTHFR as a determinant of fasting homocysteine levels, revealing an interaction between MTHFR thermolabile genotype and folate status. Individuals who are homozygotes for the MTHFR thermolabile mutation have elevated fasting homocysteine concentrations when plasma folate concentration is in the lower range but not when folate is high. We further demonstrate that thermolabile MTHFR genotype is not associated with the post-methionine load increase in plasma homocysteine, consistent with the hypothesis that post-methionine load hyperhomocysteinemia is due primarily to defects in the transsulfuration pathway. ${ }^{11}$

In conclusion, these findings indicate that individuals with thermolabile MTHFR may have a higher folate requirement for regulation of plasma homocysteine concentrations and, more importantly, suggest a therapeutic strategy (ie, folate supplementation) to prevent fasting hyperhomocysteinemia in such persons.

\section{Previous SectionNext Section}

\section{Selected Abbreviations and Acronyms}

CBS $=$ cystathionine $\beta$-synthase

FHS $\quad=$ NHLBI Family Heart Study

MTHFR = methylenetetrahydrofolate reductase

PLP = pyridoxal-5'-phosphate

Previous SectionNext Section

\section{Acknowledgments}

This project was funded in part with federal funds from the US Department of Agriculture, Agricultural Research Service under contract 53-3K06-01 and NHLBI contract N01-HC-25106 and by the Medical Research Council of Canada. The contents of this publication do not necessarily reflect the views or policies of the US Department of Agriculture.

- Received September 20, 1995.

- Revision received October 23, 1995.

- Accepted October 30, 1995. 
- Copyright (C) 1996 by American Heart Association

Previous Section

\section{References}

1. $\Perp$

Selhub J, Miller JW. The pathogenesis of homocysteinemia: interruption of the coordinate regulation by S-adenosylmethionine of the remethylation and transsulfuration of homocysteine. Am J Clin Nutr. 1991;55:131-138.

\section{$\underline{\text { Abstract/FREE Full Text }}$}

2. $\Perp$

Ueland PM, Refsum H, Stabler SP, Malinow MR, Andersson A, Allen RH. Total homocysteine in plasma or serum: methods and applications. Clin Chem. 1993;39:17641773.

\section{$\underline{\text { Abstract/FREE Full Text }}$}

3. $\Perp$

Kraus JP. Molecular basis of phenotype expression in homocystinuria. J Inherit Metab Dis. 1994;17:383-390.

CrossRefMedline

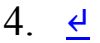

Goyette P, Sumner JS, Milos R, Duncan MV, Rosenblatt DS, Matthews RG, Rozen R. Human methylenetetrahydrofolate reductase: isolation of cDNA, mapping and mutation identification. Nat Genet. 1994;7:195-200.

$\underline{\text { CrossRefMedline }}$

5. $\Perp$

Boushey CJ, Beresford SAA, Omenn GS, Motulsky AG. A quantitative assessment of plasma homocysteine as a risk factor for vascular disease: probable benefits of increasing folic acid intakes. JAMA. 1995;274:1049-1057.

CrossRefMedline 


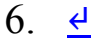

Selhub J, Jacques PF, Wilson PWF, Rush D, Rosenberg IH. Vitamin status and intake as primary determinants of homocysteinemia in the elderly. JAMA. 1993;270:2693-2698.

CrossRefMedline

7. $\Perp$

Kang S-S, Zhou J, Wong PWK, Kowalisyn J, Strokosch G. Intermediate homocysteinemia: a thermolabile variant of methylenetetrahydrofolate reductase. Am J Hum Genet. 1988;43:414-421.

$\underline{\text { Medline }}$

8. $\Perp$

Kang S-S, Wong PWK, Susmano A, Sora J, Norusis M, Ruggie N. Thermolabile methylenetetrahydrofolate reductase: an inherited risk factor for coronary artery disease. Am J Hum Genet. 1991;48:536-545.

$\underline{\text { Medline }}$

9. $\Perp$

Frosst P, Blom HJ, Milos R, Goyette P, Sheppard CA, Matthews RG, Boers GJH, den Heijer M, Kluijtmans LAJ, van den Heuvel $L$, Rozen R. A candidate genetic risk factor for vascular disease: a common mutation in methylenetetrahydrofolate reductase. Nat Genet. 1995;10:111-113.

\section{CrossRefMedline}

10.

Bostom AG, Jacques PF, Nadeau MR, Williams RR, Ellison RC, Selhub J. Postmethionine load hyperhomocysteinemia in persons with normal fasting total plasma homocysteine: initial results from the NHLBI Family Heart Study. Atherosclerosis. 1995;116:147-151.

\section{$\underline{\text { CrossRefMedline }}$}

$11 . \underline{4}$

Miller JW, Nadeau MR, Smith D, Selhub J. Vitamin B6 deficiency vs folate deficiency: comparison of responses to methionine loading in rats. Am J Clin Nutr. 1994;59:10331039. 
$\underline{\text { Abstract/FREE Full Text }}$ 